\title{
A Preliminary Exergy Analysis of the EU DEMO Fusion Reactor
}

\author{
Pierfrancesco Palazzo*, Fabio Giannetti, Gianfranco Caruso \\ Department of Astronautical, Electrical and Energy Engineering (DIAEE), Sapienza University of Rome, Corso Vittorio \\ Emanuele II, 244, Rome 00186, Italy
}

Corresponding Author Email: pierfrancesco.palazzo@gmail.com

https://doi.org/10.18280/ti-ijes.632-447

Received: 20 March 2019

Accepted: 6 May 2019

\section{Keywords:}

fusion reactor, DEMO, balance of plant, exergy balance, exergy efficiency, energy storage system

\begin{abstract}
Purpose of the present study is the exergy analysis of EU DEMO pulsed fusion power plant considering the Primary Heat Transfer Systems, the Intermediate Heat Transfer System (IHTS) including the Energy Storage System (ESS) as a first option to ensure the continuity of electric power released to the grid. A second option here considered is a methane fired auxiliary boiler replacing the ESS. The Power Conversion System (PCS) performance is evaluated as well in the overall balance. The performance analysis is based on the exergy method to specifically assess the amount of exergy destruction determined by irreversible phenomena along the whole cyclic process. The pulse and dwell phases of the reactor operation are evaluated considering the state of the art of the ESS adopting molten salts alternate heating and storage in a hot tank followed by a cooling and recovery of molten salt in a cold tank to ensure the continuity of power release to the electrical grid. The second option of the plant configuration is evaluated on the basis of an auxiliary boiler replacing the ESS with a $10 \%$ of the power produced by the reactor during both pulse and dwell modes.
\end{abstract}

\section{INTRODUCTION}

EU DEMO [1] is the pulsed fusion power plant under design in the framework of the international cooperation coordinated by the Euro fusion Consortium. The nuclear fusion with the most suitable characteristics for the industrial use is the reaction between deuterium and tritium [2]:

$$
{ }_{1} D^{2}+{ }_{1} T^{3} \rightarrow{ }_{2} \mathrm{He}^{4}(3.5 \mathrm{MeV})+n(14.1 \mathrm{MeV})
$$

The generation of Tritium, not available in the amount needed to fuel the reaction, is obtained by means of a breeding nuclear reaction occurring with Lithium nuclei, stored in the blanket of plasma chamber, according to the following reactions [2]:

$$
\begin{aligned}
& { }_{3} L i^{6}+n(14.1 \mathrm{MeV}) \rightarrow{ }_{2} \mathrm{He}^{4}(3.5 \mathrm{MeV})+{ }_{1} T^{3}+4.78 \mathrm{MeV} \\
& { }_{3} L i^{7}+n \rightarrow{ }_{2} \mathrm{He}^{4}+{ }_{1} T^{3}+n-2.47 \mathrm{MeV}
\end{aligned}
$$

These reactions, ensuring the continuity of nuclei fusion process, rely on the Tritium production in the Breeding Zone (BZ) of the blanket where thermal power is produced in addition to the amount generated by neutrons in the First Wall (FW). BZ and FW are components of the Primary Heat Transfer Systems (PHTS) and both provide a contribution to the overall thermal power conveyed to the Power Conversion System (PCS) producing the electric power released to the external grid. Two main concepts are actually proposed and developed for the EU-DEMO: Helium-Cooled Pebble Bed (HCPB) and Water-Cooled Lithium Lead (WCLL) [3]. The WCLL concept, selected as reference in this paper, is based on liquid lithium-lead eutectic as breeder and water to remove the generated heat into the blanket (through tubes inserted into the BZ and into the FW). The BZ and FW Primary Heat Transfer Systems (PHTS) are water circuits, derived from the Pressurized Water Reactors (PWR) fission power plant technology, capable to produce steam for the turbine.

Other additional heat sources are the divertor (DIV) and the vacuum vessel (VV), but the power generated is limited and at low temperature $\left(130-210^{\circ} \mathrm{C}\right)$. For this, is not possible to use DIV and VV power to produce steam and then are used as feedwater regeneration preheaters to raise the electrical efficiency.

The EU-DEMO WCLL 2017 configuration [4] has been used in the calculations.

DEMO is designed to operate in a pulsed mode through two alternated phases corresponding to a plasma burn and a dwell period. This operating sequence implies that the production of thermal power in $\mathrm{BZ}$ and $\mathrm{FW}$ of the reactor, and released to the PHTS, is not continuous and therefore this does not assure a continuity in the delivery of power from the PCS to the electric grid. The duration of plasma burn mode (pulse phase) is 2 hours while the duration of reduced heating power mode (dwell period) is 10 minutes during which only the decay heat is produced. The decay heat is approximately equal to $1 \%$ of the reaction heat produced during pulse mode thus creating a discontinuity in electric power release.

To provide a continuous power generation, an Intermediate Heat Transfer System (IHTS) is foreseen. This solution in the design of DEMO fusion reactor and the related Balance of Plant (BOP) has led to a configuration of the IHTS constituted by the secondary sides of Intermediate Heat Exchangers (IHX) and the Energy Storage System (ESS) consisting of two molten salt tanks operating at different temperatures [4]. An 
alternative option, here compared with the molten salt ESS, is represented by a natural gas (methane) fired boiler specially designed to generate the superheated steam conveyed to highand low-pressure steam turbines. Figure 1 shows a simplified process flow diagram of the whole system including main systems and components constituting the plant with ESS configuration under analysis.

\section{ENERGY STORAGE SYSTEM CONFIGURATION}

The Energy Storage System (ESS) is part of the Intermediate Heat Transfer System (IHTS) designed to feed the PCS releasing steady-state electric power to the electricity grid. The current design of the ESS is constituted by two different tanks filled in with molten salt and connected by a pipeline in which molten salt flows in two directions depending on the operating phase of the reactor [4]. During the pulse phase, the molten salt is moved from the cold tank to the hot tank after heat exchange with the cooling water conveyed from the FW PHTS. The hot tank stores the high temperature molten salt heated through two intermediate water-salt heat exchangers. The cold tank recovers the low temperature molten salt cooled during the dwell phase to produce the superheated steam conveyed to turbines of the PCS. This configuration requires the pumping of molten salt from the cold tank to the hot tank during dwell mode and vice versa during the opposite mode.

As far as the molten salt is concerned, HITEC is the commercial product of a ternary salt characterized by chemical, physical and thermodynamic properties suitable for process conditions requested by the ESS plant. HITEC is a eutectic mixture of water-soluble and inorganic salts of potassium nitrate $\mathrm{KNO}_{3}$, sodium nitrate $\mathrm{NaNO}_{3}$ and sodium nitrite $\mathrm{NaNO}_{2}$ [5] with the following composition: $7 \%$ of $\mathrm{NaNO}_{3}$, molecular weight $84.995 \mathrm{~g} / \mathrm{mol} ; 40 \%$ of $\mathrm{NaNO}_{2}$ molecular weight $69.0 \mathrm{~g} / \mathrm{mol} ; 53 \%$ of $\mathrm{KNO}_{3}$ molecular weight 101.103 $\mathrm{g} / \mathrm{mol}$; the molecular weight of the mixture equal to 87.134 $\mathrm{g} / \mathrm{mol}$.

The design of the ESS relies on the following parameters characterizing the physical properties and the behaviour of molten salt during heating and cooling phases: liquid phase specific heat, melting-solidification latent heat, maximum allowable temperature, solidification temperature, viscosity $\mathrm{v} / \mathrm{s}$ temperature, salt mass used in ESS system.

HITEC molten salt specific heat at constant pressure is $c_{p}=$ $1.56 \mathrm{~kJ} /(\mathrm{kg} \mathrm{K})$ and it is suggested to be considered as constant value with temperature independence. However, expressions are available in the literature [6] to calculate enthalpy and entropy for ESS design.

During the pulse $(2 \mathrm{~h})$ the BZ PHTS thermal power $\left(1483 M W_{t h}\right)$ is delivered to the PCS. The FW PHTS delivers a thermal power of $439.8 \mathrm{MW}_{t h}$ to the ESS: a fraction of this power is transferred to the PCS, 265.9 MW 173.9 $\mathrm{MW}_{t h}$ are stored during the pulse phase corresponding to a stored energy of $1.25 \cdot 10^{6} \mathrm{MJ}$ that will be delivered to the PCS during the dwell time. The thermal power during the pulse period is transferred from the ESS to the PCS through one Helical Coil Steam Generator (HCSG). The hot molten salt flows in shell side and transfers thermal energy to water flowing in the tube side. The molten salt temperature cycle is $280-320^{\circ} \mathrm{C}$. The feedwater enters in the HCSG with an inlet temperature of $238{ }^{\circ} \mathrm{C}$ and exits with an outlet temperature of $299^{\circ} \mathrm{C}$ at $6.41 \mathrm{MPa}$. The HCSG mass flow rate of HITEC is
$4375.4 \mathrm{~kg} / \mathrm{s}$, and the feedwater mass flow rate, calculated with the enthalpy balance, is $284.1 \mathrm{~kg} / \mathrm{s}$.

During the dwell time $(600 \mathrm{~s})$, the mass flow of molten salt from hot to cold tanks is $33436 \mathrm{~kg} / \mathrm{s}$. The ESS tank contains $20062 t$ of molten salt at the beginning of dwell, thus about $11000 \mathrm{~m}^{3}$ are needed to store this mass. In this phase, the ESS delivers power to PCS through four HCSGs. The average power available in dwell mode is approximately $2086 \mathrm{MW}$ th, thus the power of each HCSG is $521.5 M W_{t h}$. It is noteworthy that, one out of the four HCSGs is the one operating during pulse time to transfer $265.9 \mathrm{MW}$ th , as described. The thermal power recovered from Divertor Cassette, Divertor Plasma Facing Components (PFC) and Vacuum Vessel (VV), is used in the feedwater regenerative preheating through specifically designed heat exchangers. Figure 1 shows the PHTS boundary conditions accounted for in the design of the PCS carried out by means of GateCycle ${ }^{\mathrm{TM}}$ application. The output data and information have been gathered in a spreadsheet here adopted for further calculations of interest.

The objective of the present study is to provide a Second Law analysis of all components based on the exergy method to adopt a rigorous and complete approach to assess dissipation phenomena having an impact in the efficiency of the plant.

\section{METHANE FIRED STEAM GENERATOR CONFIGURATION}

An alternative option to the ESS, here evaluated and compared with the ESS, consists of an auxiliary natural gas (methane) fired steam generator to produce superheated steam during the dwell phase. Design parameters of this steam generator are derived from the process data of fusion reactor considering that the thermal power to be released during the dwell phase to ensure the continuity is some $254 \mathrm{MW}$ corresponding to the $10 \%$ of the thermal power produced during pulse mode. It is assumed a thermal energy efficiency equal to $86 \%$ considering that the economizer is missing since the feed water pre-heating occurs using the heat interaction in divertors and vacuum vessel. The fuel considered in the present analysis is $100 \%$ methane with a Low Heating Value (LHV) equal to $802.3 \mathrm{~kJ} / \mathrm{mol}=50147.5 \mathrm{~kJ} / \mathrm{kg}$. The auxiliary boiler is assumed to operate at rated power during both pulse and dwell modes. Indeed, the constant duty prevents thermal fatigue and represents and additional thermal power contribution during pulse mode.

\section{EXERGY METHOD AND ASSUMPTIONS}

The literature reports definitions and applications relating to properties underpinning the exergy method and the Second Law analysis [7-8]. The ESS is essentially characterized by the contribution of thermal energy transfer by means of heat interactions occurring in different types of exchangers. In addition, the mechanical exergy balance is accounted for. Calculation of exergy are based on the process conditions and properties deriving from the IHTS design and optimization; all data and information relating to stream interested in the present verification analysis of IHTS are those reported in the literature [1] as the result of a design project. Hence, dimensions and materials of plant components are not directly involved in this exergy analysis and, therefore, are not 
addressed to along calculations. Finally, the exergy balance is obtained from the algebraic sum of contributions pertaining to all components constituting the ESS.

As far as the dissipation processes are concerned, the heat and mass interaction flows internally to water and molten salt are neglected. Two options are considered for the PCS supply during dwell phase:

(1) ESS with molten salt hot and cold tanks;

(2) methane fuelled fired boiler for steam production.

As far as the reference system $R$ is concerned, the environment conventional conditions corresponding to $298 \mathrm{~K}$ and $1 \mathrm{bar}$ is assumed. Therefore, water is in sub-cooled liquid state and its reference thermodynamic properties to calculate exergy are the specific enthalpy $h_{R}=104.877 \mathrm{~kJ} / \mathrm{kg}$ and the specific entropy $s_{R}=0.367 \mathrm{~kJ} /(\mathrm{kg} \mathrm{K})$.

Among those thermodynamic properties of molten salt in the liquid state implied in the exergy analysis, the following expressions are here adopted for enthalpy and entropy [6]:

$h-h_{R}=\int_{298,15}^{T_{M E L T}} c_{p} d T+\Delta h_{M E L T}+\int_{T_{M E L T}}^{T} c_{p} d T=$ $0.8 \times 10^{-1} T^{2}+27.75 T-14568.9 \mathrm{~J} / \mathrm{mol}$

$s-s_{R}=\int_{298,15}^{T_{M E L T}} \frac{c_{P}}{T} d T+\frac{\Delta h_{M E L T}}{T_{M E L T}}+\int_{T_{M E L T}}^{T} \frac{c_{P}}{T} d T=1.6$. $10^{-1} T+27.75 \ln T-202.83 \mathrm{~J} /($ mol. $K)$

These properties are calculated with respect to the reference environment condition and are specially defined to calculate the thermal exergy variations along the ESS process. In order to ensure the uniformity with the unit of measure system here adopted, the numerical results of above functions are divided by the molecular weight of the molten salt to obtain $\mathrm{kJ} / \mathrm{kg}$ and $k J /(k g K)$ respectively.

Calculations have been carried out on the basis of GateCycle ${ }^{\mathrm{TM}}$ program output resulting from the design of plant configuration as described in the process flow diagram [10].

\subsection{Thermal exergy}

The canonical definition of specific thermal exergy for open bulk flow systems, through the control volume defining the contributing streams to the plant, is the following [7-8]:

$$
e x^{T}=\left(h-h_{R}\right)-T_{R}\left(s-s_{R}\right)
$$

in which $h$ and $s$ are the specific enthalpy and specific entropy at the generic thermodynamic condition of the system and $h_{R}$ and $s_{R}$ are the same properties at the reference state conditions of the reservoir represented by the environment. the above expression is used to evaluate the exergy balance of all heat exchangers operating in the plant. As far as the thermal exergy rates, the following expression is adopted that accounts for mass flowrates:

$$
\dot{E} X^{T}=\dot{m} \cdot\left(h-h_{R}\right)-T_{R}\left(s-s_{R}\right)
$$

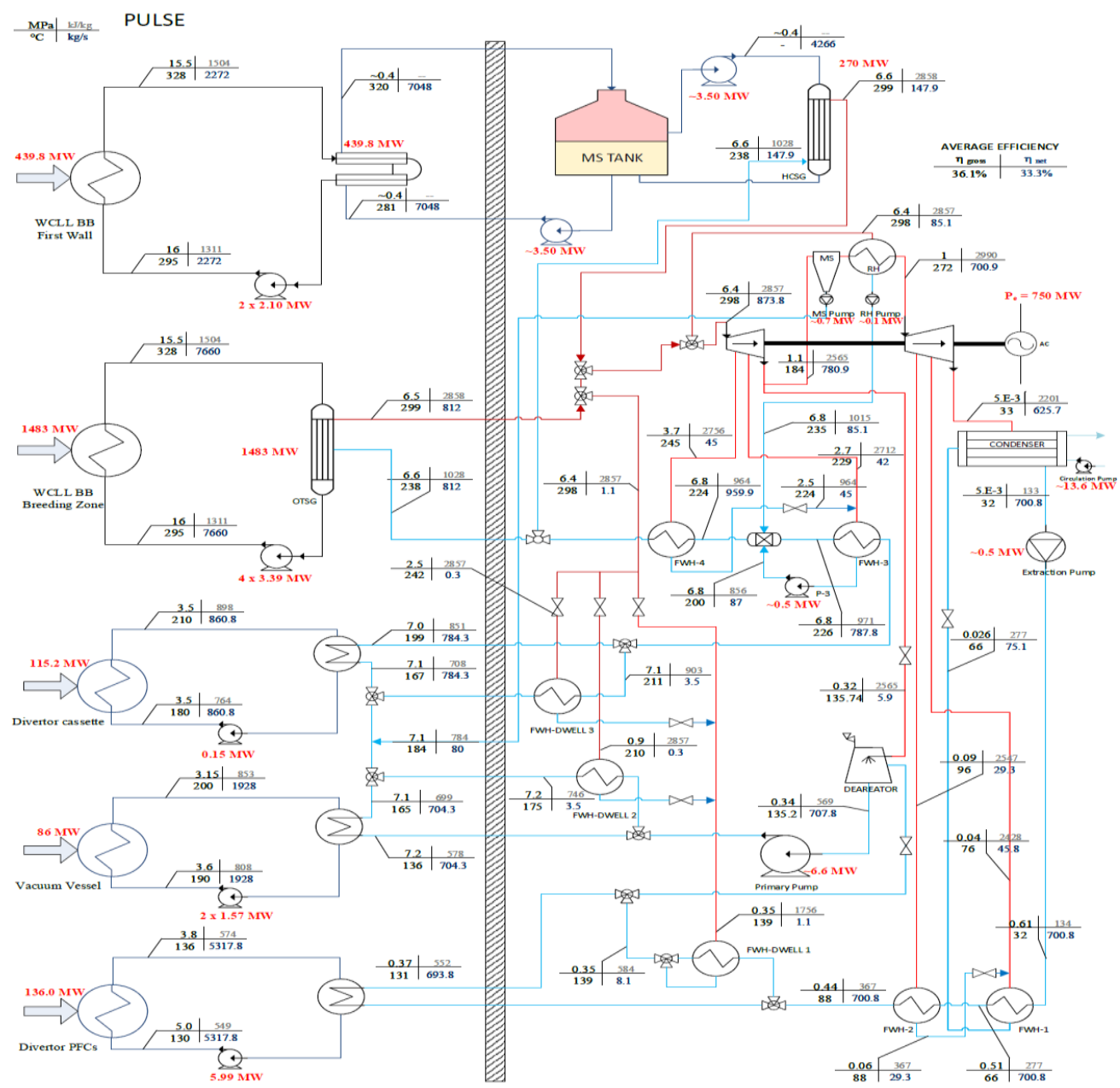

Figure 1. Process flow diagram of EU DEMO with ESS configuration 


\subsection{Chemical exergy}

The comparison of performances provided by the two plant configuration options under discussion needs to evaluate the chemical exergy of the methane combustion process in the auxiliary boiler. To do so, the canonical definition of specific molar chemical exergy for open systems is adopted. The special case of hydrocarbons can be handled considering the following typical combustion reaction:

$$
a \mathrm{CO}_{2}+\frac{b}{2} \mathrm{H}_{2} \mathrm{O} \leftrightarrow \mathrm{C}_{a} \mathrm{H}_{b}+\left(a+\frac{b}{4}\right) \mathrm{O}_{2}
$$

It relies on the molar fractions of constituents of substances and is expressed in the form here reported [7-8] based on the difference of hydrocarbon chemical potential $\mu$ before and after the reaction at the reference system represented by the environmental reservoir $R$ :

$\overline{e x}_{C_{a} H_{b}}^{C}=\mu_{C_{a} H_{b}}-\mu_{C_{a} H_{b}}^{R}$

$=\left[\bar{g}_{C_{a} H_{b}}+\left(a+\frac{b}{4}\right) \bar{g}_{O_{2}}-a \bar{g}_{C O_{2}}-\frac{b}{2} \bar{g}_{H_{2} O}\right]_{T_{R}, p_{R}}+\bar{R} T_{R} \ln \left[\frac{\left(x_{O_{2}}^{R}\right)^{a+b / 4}}{\left(x_{C O_{2}}^{R}\right)^{a}\left(x_{H_{2} O}^{R}\right)^{b / 2}}\right]$

where $x_{i}$ is the molar fraction of each $i-t h$ constituent appearing in the equation and $\bar{g}_{i}$ is the molar Gibbs chemical potential at standard conditions of $T_{R}=298.15 \mathrm{~K}$ and $p_{R}=$ $101.325 \mathrm{kPa}$

\subsection{Mechanical exergy}

The use of mechanical exergy is specially devised and here adopted to evaluate the second law performance of steam turbines [9-10]. The mechanical exergy does not account for the operating fluid mass kinetic energy and gravitational or electro-magnetic potential energy of the whole mass referred to its center of gravity. These components, termed as kinetic exergy and potential exergy respectively, are neglected when considering the balance of a plant. Then, mechanical exergy accounts for internal mechanical energy $u^{M}=u^{M}(p)=-p V$ that depends on pressure and volume entering and exiting the control volume identifying the elemental machine stage operating along an adiabatic process of a steam turbine. An adiabatic reversible process is defined as isoentropic since no heat interactions occur along the expansion (or compression) process. Then, the thermal exergy, defined in terms of maximum net useful work, with null variation of entropy in the expression $e x^{T}=\left(h-h_{R}\right)^{T}-T_{R}\left(s^{T}-s_{R}^{T}\right)$, should be coincident with the enthalpy change between input and output states, $\Delta e x^{T}=W=h_{O U T}-h_{I N}$. Though, this definition is pertaining to thermal exergy associated to the thermal internal energy $u^{T}=u^{T}(T)=T s$ while the adiabatic expansion releasing internal work is associated to the mechanical component of internal energy. Instead, the mechanical exergy, should be defined as the maximum net useful heat depending on the difference of mechanical internal energy between inlet and outlet operating fluid states. The definition $e x^{M}=$ $\left(h-h_{R}\right)^{M}+p_{R} v_{R}\left(s^{M}-s_{R}^{M}\right) \quad$ is suitable to evaluate this capability associated to pressure and the volume with respect to pressure and specific volume of the reference state of the reservoir. The term $p_{R} v\left(s^{M}-s_{R}^{M}\right)$ represents the mechanical exergy loss, or the non-useful work released to the reservoir at $p_{R} v_{R}$. Indeed, this term accounts for the fact that, although the variation of enthalpy equals the work interaction released to the external system, the capability in terms of work-to-heat conversion through and ideal cycle is not the same due to the different pressure-to-volume relationship that determines a different available mechanical internal energy. The energy loss in terms of non-useful work interaction released to the reservoir has to be accounted for in the exergy balance of steam turbines. Hence, for a steam turbine stage the following equations apply:

Input: $e x_{I N}^{M}=h_{I N}+p_{R} v_{R}\left(s_{I N}^{M}-s_{R}^{M}\right)$

Output: $W_{\text {OUT }}^{E X T} \Leftrightarrow$ ex $x_{O U T}^{M}=\left(Q_{I N-O U T}^{A R \rightarrow}\right)_{W O R K}^{M A X} e x_{O U T}^{M}=h_{\text {OUT }}+$ $p_{R} v_{R}\left(s_{\text {OUT }}^{M}-s_{R}^{M}\right)$

$e x_{D E S}^{M}=p_{R} v_{R}\left(s^{I R R}\right)^{M}$

The steam turbine mechanical exergy balance along a real process is the following:

$$
\begin{gathered}
\Delta e x^{M}=\Delta e x_{R E V}^{M}+\Delta e x_{I R R}^{M}=\left(h_{O U T}-h_{I N}\right)+p_{R} v_{R}\left(s_{O U T}^{R E V}-\right. \\
\left.s_{I N}^{R E V}\right)^{M}+p_{R} v_{R}\left(s^{I R R}\right)^{M}
\end{gathered}
$$

where the term $p_{R} v_{R}\left(s^{I R R}\right)^{M}$ represents the mechanical exergy destruction.

\subsection{Irreversible processes and exergy destruction}

Real processes imply irreversible phenomena determining an amount of entropy production. The Gouy-Stodola theorem ensures the direct relationship between entropy production and exergy destruction as expressed by the following relation [8]:

$e x_{D E S}^{T}=T_{R} S_{I R R}^{T}$

A formulation extended to all type of irreversible processes should account for chemical exergy destruction and mechanical exergy destruction, according to the following generalized version of Gouy-Stodola theorem:

$e x_{D E S}^{G}=e x_{D E S}^{T}+e x_{D E S}^{C}+e x_{D E S}^{M}=T_{R} S_{I R R}^{T}+\mu_{R} S_{I R R}^{C}+p_{R} v_{R} s_{I R R}^{M}$

That considers the generalized reservoir conditions at $T_{R}$, $\mu_{R}$ and $p_{R}$ ensuring the equality of all thermodynamic potentials and the stable equilibrium state.

\subsection{Exergy balance and exergy efficiency}

The calculation of exergy balance of a component is obtained considering the difference of exergy content of entering and exiting mass of the same stream through the control volume. However, in case of a single stream entering without exiting or, vice versa, exiting without entering, the exergy property has to be calculated based on the canonical definition with respect to the external reference system or environment.

The exergy balance is calculated in terms of exergy rate to account for the total exergy associated to the amount of mass contributing to the balance of any plant component. Therefore, for each component the balance is expressed in terms of exergy flows.

As far as the overall efficiency is concerned, the fuel and product streams are used in the literature to define the exergetic efficiency as follows: 
$\eta_{O V}^{E X}=\prod_{j=1}^{n} \eta_{j}^{E X}=\prod_{j=1}^{n} 1-\frac{E \dot{X}_{D}}{E \dot{X}_{F_{J}}}=1-\frac{E \dot{X}_{D}}{\sum_{j=1}^{m} E \dot{X}_{F_{J}}}$

where the symbols $D$ and $F$ stand for destruction and fuel respectively. Anyway, for sake of clarity and uniformity, the term input (or inlet) denoted by the symbol $I N$ will be here used in lieu of fuel.

Exergy Input:

$$
\begin{aligned}
& \dot{E X}_{P L S}=\dot{E X}_{I N}^{B Z, O T S G, H O T}+\dot{E X}_{I N}^{F W, I H X, H O T}+\dot{E} X_{I N}^{D I V, C A S}+ \\
& \dot{E X_{I N}^{D I V, P F C}}+\dot{E} X_{I N}^{V V}
\end{aligned}
$$

$$
\begin{aligned}
& \dot{E X_{D W}}=\dot{E X_{I N}^{B Z, O T S G, H O T}}+\dot{E X}_{I N}^{H C S G, H O T}+\dot{E X}_{I N}^{D I V, C A S}+ \\
& \dot{E X_{I N}^{D I V, P F C}}+\dot{E} X_{I N}^{V V}
\end{aligned}
$$

Exergy Destruction:

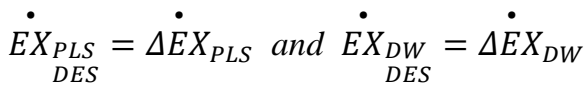

To calculate the exergy rates efficiency, exergy fuel flows considered are thermal power withdrawn from the Breeding Zone, First Wall, Divertor Cassette, Divertor PFCs, and Vacuum Vessel. The pulse-dwell sequence can be considered as a series of exergy contributions. The exergy efficiency pertaining to both modes can be calculated in terms of exergy rates. However, the expression of the overall exergy efficiency relating to the whole pulse-dwell sequence has to be obtained in terms of amount of exergy calculated along pulse and dwell time periods. The overall exergy efficiency accounts for the sum of exergy input and the sum of exergy destruction contributions during pulse and dwell modes. The expression of overall exergy efficiency characterizing ESS and auxiliary boiler configurations become the following:

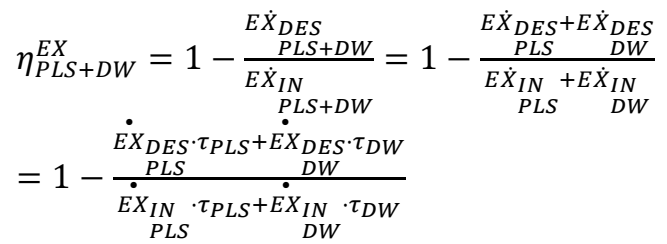

where $\tau_{P L S}$ and $\tau_{D W}$ are the time duration of pulse and dwell modes.

\section{EXERGY ANALYSES WITH ESS}

Two main phases, pulse and dwell, characterize the periodic dynamic process of thermal energy loading and unloading of the molten salt storage system. This alternate operation ensures the constant electric power input in the grid as an output of Power Conversion System (PCS). Analyses along both pulse and dwell processes account for all components and the results are those produced by GateCycle ${ }^{\mathrm{TM}}$ and the spreadsheet adopted to gather all data and information and to carry out the exergy analyses based on those previous predesign and balances [11]. Following figures are specially focusing on BZ PHTS and FW PHTS directly conveyed to the OTSG and to PCS to highlight main components of the PHTS representing the fuel exergy input in the expression of exergy efficiency. Instead, Divertor Cassette, Divertor PFCs and
Vacuum Vessel components, used for feedwater pre-heating in both pulse and dwell modes, are anyway duly accounted for in balances and efficiencies calculations, in particular for the exergy destruction contributions due to irreversible phenomena in all plant components.

\subsection{Pulse mode exergy balance}

The calculation of thermal exergy variation requires enthalpy and entropy corresponding to the inlet and outlet states of water, steam and molten salts. The following figures are obtained from water and steam tables. As concerns the chemical, physical and thermodynamic properties of HITEC reference is made to data available from commercial data sheets and literature.

\subsubsection{BZ PHTS}

During the pulse mode ( 2 hours) the primary cooling water flowing through the $\mathrm{BZ}$ of the plasma chamber conveys a thermal power, equal to $2 \cdot 741.5=1483 M W_{t h}$, to two Once Through Steam Generator (OTSG) from which superheated steam is delivered to PCS steam turbines.

The OTSG primary side (hot) pressure is $15.5 \mathrm{MPa}$ and the total water mass flow rate is $2 \cdot 3847=7694 \mathrm{~kg} / \mathrm{s}$.

The OTSG secondary side (cold) pressure is assumed 6.41 $\mathrm{MPa}$ and super-heated steam is produced and conveyed to the steam turbines of the Power Conversion System (PCS). The secondary side water mass flow rate per each OTSG is $2 \times 406=812 \mathrm{~kg} / \mathrm{s}$.

Inlet and outlet temperatures in the BZ OTSG Primary (tube-side, TB) are: $T_{I N}^{B Z, O T S G, T B}=328^{\circ} \mathrm{C}=601 \mathrm{~K}$ and $T_{\text {OUT }}^{B Z, O T S G, T B}=295^{\circ} \mathrm{C}=568 \mathrm{~K}$.

Feedwater coolant inlet and superheated steam outlet temperatures in the BZ OTSG Secondary (shell-side, $\mathrm{SH}$ ) are: $T_{I N}^{B Z, O T S G, S H}=238^{\circ} \mathrm{C}=511 \mathrm{~K}$ and $T_{\text {OUT }}^{B Z, O T S G, S H}=299^{\circ} \mathrm{C}=$ $572 K$

The thermal exergy balance of OTSG results from the contributions due to the thermal exergy release along the shell side and the thermal exergy increase along the tube side. Therefore, the thermal exergy destruction is calculated by means of the following component balance expression:

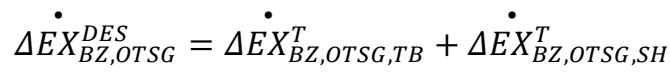

\subsubsection{FW PHTS}

The FW PHTS is designed to recover the thermal power 439.8 $\mathrm{MW}_{t h}=2 \cdot 219.9 \mathrm{MW}$ th produced during the pulse mode $(2 \mathrm{~h})$ and use it to store thermal energy $\left(1.25 \cdot 10^{6} \mathrm{MJ}\right)$ in the molten salt that will be used during the dwell phase to produce electric power ensuring the continuity to the power output into the electrical grid. The two Intermediate Heat Exchangers (IHX) transfer the thermal power, recovered from FW PHTS by the cooling water flowing in the primary side at 15.5 MPa with a mass flowrate of $2272 \mathrm{~kg} / \mathrm{s}$, to the HITEC molten salt circulating in the secondary side with a mass flowrate of $4375.4 \mathrm{~kg} / \mathrm{s}$ from the cold tank to the hot tank.

The two Intermediate Heat Exchangers (IHX) are specifically designed to convey heat interaction from FW to the molten salt to be stored in the hot tank. IHX primary side (hot) water temperatures are the following: $T_{I N}^{F W, I H X, T B}=$ $328{ }^{\circ} \mathrm{C}=601 \mathrm{~K}$ and $T_{O U T}^{F W, I H X, T B}=295^{\circ} \mathrm{C}=568 \mathrm{~K}$;

During the $2 \mathrm{~h}$ pulse mode, the IHX secondary side (cold) HITEC molten salt mass flow rate from cold to hot tank is 
$4375.4 \mathrm{~kg} / \mathrm{s}$. The inlet and outlet temperatures are: $T_{I N}^{F W, I X H, S H}=280{ }^{\circ} \mathrm{C}=553 \mathrm{~K}$ and $T_{O U T}^{F W, I X H, S H}=320^{\circ} \mathrm{C}=$ $593 \mathrm{~K}$. The thermal entropy is calculated considering that molten salts undergo an isovolumic process, therefore, the expression is $\quad \Delta S^{T}=\int_{0}^{1} \frac{C_{v} d T}{T} \cong \int_{0}^{1} \frac{C_{p} d T}{T}=C_{p} \ln \frac{T_{1}}{T_{0}}=$ $C_{p} \ln \frac{T_{\text {OUT }}}{T_{I N}}$ applied to sensible heat and latent heat during melting so that the thermal exergy is: $\Delta \dot{E} X^{F W, I X H, S H}=\dot{m}$. $\left(\Delta h-T_{R} \Delta s^{T}\right)^{F W, I X H, S H}$ where the experimental expression of enthalpy and thermal entropy depending on temperature for molten salt applications is shown in the previous Sect. 4. and reported in the literature [6].

The thermal exergy balance of IHXs results from the contributions due to the thermal exergy release along the shell side and the thermal exergy increase along tube side. Therefore, the thermal exergy destruction is calculated by means of the following component balance expression:

$\Delta \dot{E X_{F W, I H X}^{D E S}}=\Delta \dot{E X_{F W, I H X, T B}^{T}}+\Delta \dot{E} \dot{X}_{F W, I H X, S H}^{T}$

During the pulse mode, the circulation through OTSG and IHX requires mechanical power to be spent and dissipated along the circuit.

The amount of mechanical power moving the BZ cooling water through OTSG shell side is 7.2 $\mathrm{MW}$. As regard the tube side of OTSGs, the mechanical power results from the contribution of condenser extraction pump equal to $0.3 \mathrm{MW}$, and the circulation pump equal to $5 M W$ resulting in a total amount of $5.3 \mathrm{MW}$, therefore $\triangle \dot{E X}_{\mathrm{BZ}, \mathrm{OTSG}}^{\mathrm{M}}=12.5 \mathrm{MW}$.

The power moving the FW cooling water through IHXs tube side is $2.1 \mathrm{MW}$. For IHXs shell side, molten salts are moved from the cold tank to the hot tank by means of pumps delivering a mechanical power equal to $3.5 \mathrm{MW}$, therefore $\Delta \dot{E X}_{I H X}^{M}=5.6 \mathrm{MW}$.

Finally, the total amount of mechanical power during pulse mode results in the destruction of mechanical exergy dissipated along the motion and resulting in the pressure loss; the balance of mechanical exergy destruction is the following:

$\Delta \dot{E X}_{P L S}^{M}=\Delta \dot{E X}_{B Z, O T S G}^{M}+\Delta \dot{E X}_{F W, I H X}^{M}=18.1 \mathrm{MW}$

The total exergy balance related to pulse mode includes the OTSG and IHX thermal exergy and mechanical exergy flow.

$\dot{E}_{P L S}=\Delta \dot{E}_{P L S}^{T}+\Delta \dot{E} X_{P L S}^{M}$

Table 1 summarizes the exergy analysis of this configuration in pulse mode.

\subsection{Dwell mode exergy balance}

Similarly to the case of pulse mode, the thermal exergy balance in dwell mode requires enthalpy and entropy properties corresponding to the inlet and outlet states of molten salts, water and superheated steam flowing through four Helical Coil Steam Generators.
Table 1. DEMO exergy input and exergy destruction with ESS in pulse mode

\begin{tabular}{|c|c|c|c|c|c|}
\hline \multicolumn{6}{|c|}{ DEMO Configuration with ESS - Pulse Mode } \\
\hline $\begin{array}{c}\text { PHTS } \\
\text { COMPONENT }\end{array}$ & $\dot{m}(\mathrm{~kg} / \mathrm{s})$ & $\begin{array}{c}\mathrm{s}(\mathrm{kJ} /(\mathrm{kg} \\
\mathrm{K}))\end{array}$ & $\mathrm{ex}(\mathrm{kJ} / \mathrm{kg})$ & $\begin{array}{l}\dot{E X_{I N}} \\
(\mathrm{MW})\end{array}$ & $\begin{array}{l}\dot{E} X_{D E S} \\
(\mathrm{MW})\end{array}$ \\
\hline $\begin{array}{l}\text { BZ OTSG Hot } \\
\text { Inlet }\end{array}$ & 7694.67 & 3.508 & 462.72 & 3560.5 & -45.14 \\
\hline $\begin{array}{l}\text { FW IHX Hot } \\
\text { Inlet }\end{array}$ & 2272.0 & 3.706 & 402.89 & 915.36 & -4.21 \\
\hline $\begin{array}{c}\text { Divertor Cass. } \\
\text { Hot Inlet }\end{array}$ & 860.8 & 2.422 & 180.98 & 155.79 & -2.46 \\
\hline $\begin{array}{c}\text { Divertor PFCs } \\
\text { Hot Inlet } \\
\text { Vacuum }\end{array}$ & 5317.85 & 1.694 & 73.91 & 393.04 & -6.605 \\
\hline $\begin{array}{l}\text { Vessel Hot } \\
\text { Inlet }\end{array}$ & 1927.68 & 2.328 & 163.66 & 315.48 & -6.349 \\
\hline
\end{tabular}

\subsubsection{Helical coil steam generators}

The Helical Coil Steam Generators (HCSG) are designed to transfer the thermal energy stored in the hot molten salt to the feedwater to generate the superheated steam to be expanded in steam turbines. During dwell time of 10 minutes, the hot molten salt stored in the hot tank is delivered to four HCSGs before being recovered in the cold tank. The molten salt flows from hot tank to cold tank through HCGS shell side and releases the thermal power to the feedwater flowing in the tube side with a mass flow rate of $4 \cdot 255=1020 \mathrm{~kg} / \mathrm{s}$ $(3672 t / h)$ at 6.41 MPa and exits as superheated steam conveyed to be expanded in steam turbines of PCS

The HCSG shell side molten salt temperatures are [3]: $T_{I N}^{H C S G, S H}=320^{\circ} \mathrm{C}=593 \mathrm{~K}$ and $T_{O U T}^{H C S G, S H}=553 \mathrm{~K}$. The enthalpy is calculated as: $\Delta H^{H C S G, S H}=C_{P}\left(T_{O U T}^{H C S G, S H}-\right.$ $\left.T_{I N}^{H C S G, S H}\right)$; the absolute value of enthalpy variation is equal during pulse and dwell phases as no energy accumulation is foreseen in the molten salts. Also in this case, the thermal entropy is calculated by means of the same expression already adopted for the pulse phase in this case expressing an entropy decrease due to cooling, corresponding to the entropy increase of molten salt heating during the pulse phase.

The thermal exergy flow input needed to calculate the exergy efficiency is the following:

$$
\begin{aligned}
& \dot{E X}_{I N P}^{H C S G, T B}=\dot{m} \cdot\left[\left(h_{I N}^{H C S G, T B}-h_{R}\right)-T_{R}\left(s_{I N}^{H C S G, T B}-s_{R}\right)\right]= \\
& \dot{m} \cdot\left[c_{P}\left(T_{I N}^{H C S G, S H}-T_{R}\right)-T_{R} c_{p} \ln \frac{T_{I N}^{H C S G, S H}}{T_{R}}\right]
\end{aligned}
$$

Feedwater temperature in tube side is increased by the heat interaction with the molten salt releasing a thermal power. Hence, from liquid water at $T_{I N}^{H C S G, T B}=238^{\circ} \mathrm{C}=511 \mathrm{~K}$ to superheated steam $T_{O U T}^{H C S G, T B}=299{ }^{\circ} \mathrm{C}=572 \mathrm{~K}$ conveyed to the high pressure steam turbine.

So far, a thermal exergy balance has been calculated. However, mechanical exergy balance due to pressure loss along interconnecting piping designed to convey molten salt should be accounted for in both pulse and dwell phases to achieve an overall assessment of thermal and mechanical dissipation phenomena occurring in the ESS during both operating phases. To do so, the mechanical exergy destruction rate is calculated considering that it corresponds to the mechanical power delivered by pumps to all circulating fluids.

During dwell mode, molten salt is moved from the hot tank to the cold tank by means of pumps delivering mechanical 
power equal to $14 \mathrm{MW}$. Therefore: $\triangle \dot{E}_{D W}^{M}=\Delta \dot{E} X_{H C S G}^{M}=$ $14 M W$

The total exergy balance during dwell mode includes the HCSG thermal exergy and mechanical exergy flow.

$\Delta \dot{E X}_{D W}=\Delta \dot{E}_{D W}^{T}+\Delta \dot{E X}_{D W}^{M}$
The exergy analysis in dwell mode is shown in Table 2.

The thermal power produced in the Divertor Cassette, Divertor PFCs and Full Vacuum is conveyed to the regeneration system design to pre-heat the feedwater before inlet in OTSG during both pulse and dwell modes and to IHX during pulse mode only. Pre-heaters are U-Tubes and Shell heat exchangers.

Table 2. DEMO exergy input and exergy destruction with ESS in Dwell mode

\begin{tabular}{|c|c|c|c|c|c|}
\hline \multicolumn{6}{|c|}{ DEMO Configuration with ESS - Dwell Mode } \\
\hline $\begin{array}{c}\text { PHTS } \\
\text { COMPONENT }\end{array}$ & $\dot{m}(\mathrm{~kg} / \mathrm{s})$ & $\begin{array}{c}s(\mathrm{~kJ} /(\mathrm{kg} \\
\mathrm{K}))\end{array}$ & $\operatorname{ex}(\mathrm{kJ} / \mathrm{kg})$ & $\begin{array}{l}\dot{E} X_{I N} \\
\text { (MW) }\end{array}$ & $\begin{array}{l}\dot{E} X_{D E S} \\
\text { (MW) }\end{array}$ \\
\hline $\begin{array}{l}\text { MS HCSG Hot } \\
\text { Inlet }\end{array}$ & 10196.39 & 3.508 & 458.26 & 4672.57 & -60.33 \\
\hline $\begin{array}{l}\text { BZ OTSG Hot } \\
\text { Inlet }\end{array}$ & 50.97 & 3.508 & 462.72 & 23.59 & -0.315 \\
\hline $\begin{array}{c}\text { Divertor Cass. } \\
\text { Hot Inlet }\end{array}$ & 860.8 & 2.28 & 155.76 & 134.08 & 0.0124 \\
\hline $\begin{array}{c}\text { Divertor PFCs } \\
\text { Hot Inlet }\end{array}$ & 5317.80 & 1.663 & 70.47 & 374.76 & -0.376 \\
\hline $\begin{array}{c}\text { Vacuum } \\
\text { Vessel Hot } \\
\text { Inlet }\end{array}$ & 1927.68 & 2.281 & 155.45 & 299.65 & -0.325 \\
\hline
\end{tabular}

\subsection{Exergy balance and efficiency}

The overall exergy balance of the IHTS, including the ESS, is calculated over the two pulse and dwell phases to take a pulse-dwell closed cycle as the reference unit operation. In order to properly compare the two phases, the exergy efficiency is calculated based on the exergy amount during each reactor operating mode time duration. Therefore:

$\Delta E X_{O V}=\Delta E X_{P L S}+\Delta E X_{D W}$

Pulse Mode: the exergy efficiency during pulse mode is calculated by means of the following expression:

$\eta_{P L S}^{E X}=1-\frac{\dot{\Delta E} X_{P L S}^{O V, D E S}}{\dot{E} X_{I N}^{B Z, O T S G, H O T}+\dot{E} \dot{X}_{I N}^{F W, I H X, H O T}+\dot{E} \dot{X}_{I N}^{D I V, C A S}+\dot{E} X_{I N}^{D I V, P F C}+\dot{E} \dot{X}_{I N}^{V V}}$

Dwell Mode: the exergy efficiency during dwell mode is calculated by means of the following expression:

$\eta_{D W}^{E X}=1-\frac{\dot{\Delta E} X_{D W}^{O V, D E S}}{\dot{E} X_{I N}^{B Z, O T S G, H O T}+\dot{E} X_{I N}^{H C S G, H O T}+\dot{E} \dot{X}_{I N}^{D I V, C A S}+\dot{E} X_{I N}^{D I V, P F C}+\dot{E} X_{I N}^{V V}}$

\section{EXERGY ANALYSES WITH AUXILIARY BOILER REPLACING ESS}

A viable alternative solution to reduce plant layout complexity and due to molten salt tanks and connection piping is to replace the ESS with an auxiliary boiler. This fired steam generator is evaluated being fuelled by natural gas $(100 \%$ methane $\mathrm{CH}_{4}$ ) and provides thermal power production during the dwell phase. The design thermal duty of this steam generator is about $254 \mathrm{MW}$ as it is foreseen that, during dwell phase, $10 \%$ of the mass flow rate, and hence thermal power released with respect to pulse phase, is considered for plant operation. Moreover, to avoid thermal fluctuations and consequent thermal fatigue, the auxiliary steam generator is operated in continuous mode during both pulse and dwell phases to ensure a constant duty. This implies that the thermal power released by the auxiliary boiler has to be considered during pulse mode in addition to that thermal power not used for molten salt heating. Therefore, the entire thermal power produced by the reactor during pulse mode is available for the PCS and provided by four OTSG operating in parallel to use the thermal power generated in both breeding zone and first wall. The combustions reaction can be written as follows:

$\alpha \mathrm{CH}_{4}+x\left(\mathrm{O}_{2}+3.76 \mathrm{~N}_{2}\right) \rightarrow a C \mathrm{O}_{2}+b \mathrm{H}_{2} \mathrm{O}+c \mathrm{~N}_{2}+d \mathrm{O}_{2}$

The standard specific molar chemical exergy of methane, with respect to the reference reservoir $R$ represented by the environment at $T_{R}=298.15 \mathrm{~K}$ and $p_{R}=101.325 \mathrm{kPa}$ is [12]:

$\overline{e x}_{C H_{4}}^{C}=\mu_{C H_{4}}\left(T_{R}, p_{R}\right)-\mu_{C H_{4}}^{R}\left(T_{R}, p_{R}\right)=831.2 \mathrm{~kJ} / \mathrm{mol}$

Considering the molar weight of methane equal to $16.04 \mathrm{~g} / \mathrm{mol}$, then the specific chemical exergy is:

$e x_{C H_{4}}^{C}=\frac{831.2 \mathrm{~kJ} / \mathrm{mol}}{16.04 \mathrm{~g} / \mathrm{mol}} \cong 51.82 \mathrm{~J} / \mathrm{kg}$

The Lower Heating Value (LHV) of the methane is $802.3 \mathrm{~kJ} / \mathrm{mol}=50147.5 \mathrm{~kJ} / \mathrm{kg}$, then the mass flowrate expressed in $\mathrm{mol} / \mathrm{s}$ of methane needed to produce $254 \mathrm{MW}$ of thermal power is obtained considering an auxiliary boiler with no economizer as pre-heating is no needed; then its design implies a lower thermal efficiency equal to $\eta_{B O I L E R}=0.86$. Thus, the methane mass flowrate is:

$\frac{\dot{Q}}{\eta_{B O I L E R} \cdot L H V} \cong 368.14 \frac{\mathrm{mol}}{\mathrm{s}}=5.905 \frac{\mathrm{kg}}{\mathrm{s}}$

This is the mass flowrate that is to be accounted for exergy balance with the option of auxiliary boiler to producing $254 M W$ of thermal power.

The air mass flowrate, considering air excess of $10 \%$, is equal to $117.32 \mathrm{~kg} / \mathrm{s}$.

The temperature at the center of the burning flame in the 
combustion chamber can be assumed at $2000^{\circ} \mathrm{C}=2273 \mathrm{~K}$.

The rate of exergy destruction is calculated as follows:

$\dot{E}_{D E S}=\Delta \dot{E X}_{D E S}^{T}+\Delta \dot{E X}_{D E S}^{C}=\dot{E X}_{I N}-\Delta \dot{E X_{O U T}}$

where $\dot{E} X_{I N}=$ heat losses to environment + thermal exergy input + chemical exergy input

$$
\begin{gathered}
\dot{E} X_{I N}=0.02 \cdot 5.905 \cdot 50147.5 \cdot\left(1-\frac{298}{2273}\right)+117.32 \cdot \cdot \\
281.7+5.905 \cdot 1.06 \cdot 50147.5 \approx 352083 \mathrm{~kJ} / \mathrm{s}
\end{gathered}
$$

$\Delta \dot{E X}_{\text {OUT }}=(5.905+117.32) \cdot 957.42=117978 \mathrm{~kJ} / \mathrm{s}$

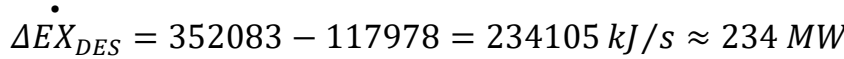

Tables 3 and 4 include all calculated values pertaining to pulse and dwell mode respectively, of the configuration with auxiliary boiler.

Table 3. DEMO exergy input and exergy destruction with

\begin{tabular}{|c|c|c|c|c|c|}
\hline \multicolumn{6}{|c|}{ DEMO Configuration with Auxiliary Boiler - Pulse Mode } \\
\hline $\begin{array}{c}\text { PHTS } \\
\text { COMPONENT }\end{array}$ & $\dot{m}(\mathrm{~kg} / \mathrm{s})$ & $\begin{array}{c}s(\mathrm{~kJ} / \mathrm{kg} \\
\mathrm{K})\end{array}$ & $e x(\mathrm{~kJ} / \mathrm{kg})$ & $\begin{array}{l}E X_{I N} \\
(\mathrm{MW})\end{array}$ & $\begin{array}{l}\dot{E} X_{D E S} \\
(\mathrm{MW})\end{array}$ \\
\hline $\begin{array}{c}\text { BZ + FW } \\
\text { OTSG Hot } \\
\text { Inlet }\end{array}$ & 9981.8 & 3.51 & 462.72 & 4618.84 & -69.61 \\
\hline $\begin{array}{c}\text { Auxiliary } \\
\text { Burner } \\
\text { CH4 LHV } \\
\text { Inlet }\end{array}$ & 5.905 & 11.59 & 50147.0 & 313.88 & -234.0 \\
\hline $\begin{array}{c}\text { Divertor Cass. } \\
\text { Hot Inlet }\end{array}$ & 860.8 & 2.42 & 180.98 & 155.78 & -3.360 \\
\hline $\begin{array}{c}\text { Divertor PFCs } \\
\text { Hot Inlet } \\
\text { Vacuum }\end{array}$ & 5317.85 & 1.69 & 73.91 & 393.04 & -5.114 \\
\hline $\begin{array}{l}\text { Vessel Hot } \\
\text { Inlet }\end{array}$ & 1927.68 & 2.33 & 163.66 & 315.48 & -6.312 \\
\hline
\end{tabular}
auxiliary boiler in pulse mode

Table 4. DEMO exergy input and exergy destruction with

\begin{tabular}{|c|c|c|c|c|c|}
\hline \multicolumn{6}{|c|}{ DEMO Configuration with Auxiliary Boiler- Dwell Mode } \\
\hline $\begin{array}{c}\text { PHTS } \\
\text { COMPONENT }\end{array}$ & $\dot{m}(\mathrm{~kg} / \mathrm{s})$ & $\begin{array}{c}s(\mathrm{~kJ} /(\mathrm{kg} \\
\mathrm{K}))\end{array}$ & $\operatorname{ex}(\mathrm{kJ} / \mathrm{kg})$ & $\begin{array}{l}\dot{E} X_{I N} \\
(\mathrm{MW})\end{array}$ & $\begin{array}{l}\dot{E} X_{D E S} \\
(\mathrm{MW})\end{array}$ \\
\hline $\begin{array}{c}\text { BZ + FW } \\
\text { OTSG Hot } \\
\text { Inlet }\end{array}$ & 65.35 & 3.508 & 462.723 & 30.239 & -0.514 \\
\hline $\begin{array}{c}\text { Auxiliary } \\
\text { Burner } \\
\text { CH4 LHV } \\
\text { Inlet }\end{array}$ & 5.91 & 11.59 & 50147.0 & 313.882 & -234.0 \\
\hline $\begin{array}{c}\text { Divertor Cass. } \\
\text { Hot Inlet }\end{array}$ & 860.8 & 2.28 & 155.758 & 134.076 & -0.0104 \\
\hline $\begin{array}{c}\text { Divertor PFCs } \\
\text { Hot Inlet } \\
\text { Vacuum }\end{array}$ & 5317.85 & 1.663 & 70.473 & 374.763 & -0.1726 \\
\hline $\begin{array}{c}\text { Vessel Hot } \\
\text { Inlet }\end{array}$ & 1927.68 & 2.281 & 155.447 & 299.652 & -0.0429 \\
\hline
\end{tabular}
auxiliary boiler in dwell mode

\subsection{Exergy balance and efficiency}

Similarly to the configuration with ESS, also in the case with the auxiliary boiler the exergy efficiency is calculated based on the exergy amount during each reactor operating mode time duration.

Pulse Mode

$\eta_{P L S}^{E X}=1-\frac{\dot{\Delta E} X_{P L S}}{\dot{E} X_{P L S}}=1-\frac{\dot{\Delta E} X_{P L S}}{\dot{E} X_{I N}^{O T S G, S H}}$

Dwell Mode

$\eta_{D W}^{E X}=1-\frac{\dot{\Delta E} X_{D W}}{\underset{E}{E X_{D W}}}=1-\frac{\dot{\Delta E} X_{D W}}{\dot{E} X_{I N}^{O T S G, S H}}$

\section{EXERGY EFFICIENCY OF THE OVERALL PULSE- DWELL CYCLE}

The comparison of performances achieved by the two configurations of BOP should summarize the properties along both pulse and dwell modes to merge the results in one indicator, namely the exergy efficiency. To do so, the efficiency is calculated considering the amount of exergy input and destruction, instead of use the rates as previously done. Then, input and destruction exergy rates must be multiplied by the duration of pulse and dwell mode to obtain an exergy amount that can be summed up and used in the efficiency expression. Thus, considering all figures calculated for ESS and auxiliary boiler configuration during pulse and dwell modes, the following result is obtained.

Configuration with ESS:

Pulse (7200 s)

Input:

$\underset{P L S}{E X_{I N}} \cdot \tau_{P L S}=\underset{P L S}{E X_{I N}}=38.448 \cdot 10^{6} M J$

Destruction:

$$
\underset{P L S}{\stackrel{E X_{D E S}}{P}} \cdot \tau_{P L S}=\underset{P L S}{E X_{D E S}}=3.9744 \cdot 10^{6} \mathrm{MJ}
$$

Dwell (600 s)

Input:

$\underset{D W}{E X_{I N}} \cdot \tau_{D W}=\underset{D W}{E X_{I N}}=3.3024 \cdot 10^{6} M J$

Destruction:

$\stackrel{E_{D E S}}{X_{D W}} \cdot \tau_{D W}=E X_{D E S}=0.3516 \cdot 10^{6} \mathrm{MJ}$

$\eta_{E S S}^{E X}=1-\frac{E X_{D E S}+E X_{D E S}}{D X_{I N}+E X_{I N}}=1-\frac{3.9744+0.3516}{38.448+3.3024}=1-\frac{4.326}{41.7504}=$ 0.8964

Configuration with Auxiliary Boiler:

Pulse (7200 s)

Input: 
$\underset{P L S}{\dot{E X_{I N}}} \cdot \tau_{P L S}=\underset{P L S}{E X_{I N}}=42.5808 \cdot 10^{6} \mathrm{MJ}$

Destruction:

$\underset{P L S}{\dot{E X_{D E S}}} \cdot \tau_{P L S}=\underset{P L S}{E X_{D E S}}=6.0408 \cdot 10^{6} \mathrm{MJ}$

Dwell (600 s)

Input:

$\underset{D W}{E X_{I N}} \cdot \tau_{D W}=\underset{D W}{E X_{I N}}=0.7008 \cdot 10^{6} \mathrm{MJ}$

Destruction:

$$
\begin{aligned}
& \underset{D W}{E X_{D E S}} \cdot \tau_{D W}=\underset{D W}{E X_{D E S}}=0.183 \cdot 10^{6} \mathrm{MJ} \\
& \eta_{C H 4}^{E X}=1-\frac{\begin{array}{c}
E X_{D E S}+E X_{D E S} \\
P W
\end{array}}{\underset{P X_{I N}+E X_{I N}}{P L S}{ }_{D W}}=1-\frac{6.0408+0.183}{42.5808+0.7008}=1- \\
& \frac{6.2238}{43.2816}=0.8562
\end{aligned}
$$

All results related to exergy efficiency above achieved are summarized in the following Table 5:

Table 5. DEMO exergy efficiencies

\begin{tabular}{ccc}
\hline & $\begin{array}{c}\text { Exergy Rates } \\
\text { Efficiency }\end{array}$ & Exergy Efficiency \\
\hline with ESS & $89.66 \%$ & \\
Pulse & $89.35 \%$ & \\
Dwell & & $89.64 \%$ \\
Overall & & \\
with Auxiliary Boiler & $85.81 \%$ & \\
Pulse & $73.82 \%$ & $85.62 \%$ \\
Dwell & & \\
Overall & & \\
\hline
\end{tabular}

\section{CONCLUSIONS}

Main result of the present research is a performance evaluation based on exergy method adopted to calculate balances and efficiencies of components and systems constituting the overall plant. The second Law, underpinning the exergy method, focuses on dissipative phenomena implying entropy production and exergy destruction representing performance indicator to detect solution for the design enhancement. The PHTS, IHTS, ESS and PCS of DEMO fusion reactor and balance of plant assessed by means of the exergy method reveals that the efficiency of the system designed with molten salts remains higher with respect to the alternative solution with an auxiliary boiler replacing the ESS. The difference of exergy efficiency between the solutions here considered could suggest the suitability of both configurations. Nevertheless, on the one side, the strong exergo-dissipative combustion reaction that would lower the performance with the auxiliary boiler is mitigated by the thermal power reduction to $10 \%$ during dwell mode. Though, this solution determines a higher stress level and fatigue in steam turbine components. On the other side, the ESS with molten salt ensures the continuity of full power release; moreover, this configuration could undergo design improvements based on optimized shapes of intermediate heat exchangers derived from the entropy generation minimization underpinning the Constructal Law and Constructal Thermodynamics approach [13] specifically applied to heat interactions phenomena and heat exchangers design [14]. Anyway, the selection of the most suitable option requires a more accurate evaluation of the balance of plant in terms of reliability and economics considering the location of the plant and the need of additional infrastructures.

\section{ACKNOWLEDGMENT}

This study has been carried out within the framework of the EURO fusion Consortium and has received funding from the Euratom research and training programme 2014-2018 and 2019-2020 under grant agreement No 633053. The views and opinions expressed herein do not necessarily reflect those of the European Commission

\section{REFERENCES}

[1] Federici G, Bachmann C, Barucca L, Biel W, Boccaccini L, Brown R, Bustreo C, Ciattaglia S, Cismondi F, Coleman M, Corato V, Day C, Diegele E, Fischer U, Franke T, Gliss C, Ibarra A, Kembleton R, You JH. (2018). DEMO design activity in Europe: Progress and updates. Fusion Engineering and Design 136: 729-741. https://doi.org/10.1016/j.fusengdes.2018.04.001

[2] Stacey WM, Steiner D. (2010). Fusion: An introduction to physics and technology of magnetic confinement $\begin{array}{llll}\text { fusion. } & \text { Physics } & \text { Today } & \end{array}$ http://dx.doi.org/10.1063/1.2814671

[3] Martelli E, Del Nevo A, Arena P, Bongiovi G, Caruso G, Maio PAD, Eboli M, Mariano G, Marinari R, Moro F, Mozzillo R, Giannetti F, Gironimo GD, Tarallo A, Tassone A, Villari R. (2018). Advancements in DEMO WCLL breeding blanket design and integration. International Journal of Energy Research 42(1): 27-52. https://doi.org/10.1002/er.3750

[4] Martelli E, Giannetti F, Caruso G, Tarallo A, Polidori M, Barucca L, Del Nevo A. (2018). Study of EU DEMO WCLL breeding blanket and primary heat transfer system integration. Fusion Engineering and Design 136: 828-833.

Https://doi.org/10.1016/j.fusengdes.2018.04.016

[5] Coastal Chemical Co., L.L.C.-HITEC® Heat Transfer Salt Technical Brochure.

[6] Tao W. (2011). High Thermal Energy Storage Density Molten Salts for Parabolic Through Solar Power Generation. MSc thesis, Tuscaloosa, Alabama.

[7] Moran MJ, Sciubba E. (1994). Exergy analysis: Principles and practice. Journal of Engineering for Gas $\begin{array}{lll}\text { Turbines and } & \text { Power }\end{array}$ https://doi.org/10.1115/1.2906818

[8] Kotas TJ. (1995). The Exergy Method of Thermal Plant Analysis. Reprint edn; Krieger Publishing Company.

[9] Palazzo P. (2014). Performance optimization of the carnot and joule cycles and relationship with the formulation of physical exergy property. British Journal of Applied Science and Technology 4(2): 261-278. https://doi.org/10.9734/BJAST/2014/6384 
[10] Palazzo P. (2014). Dualisms and symmetries in physical exergy property and generalized formulation related to the carnot and joule cycles. British Journal of Applied Science and Technology 4(11): 1594-1608. https://doi.org/10.9734/BJAST/2014/7727

[11] Padula G. (2018). EU-DEMO WCLL balance of plant: Power conversion system analysis and preliminary design. MSc thesis, Sapienza Università di Roma, Rome, Italy.

[12] Szargut J. (2005). Exergy method. Technical and Ecological Applications, WIT Press, Southampton, UK.

[13] Bejan A. (2016). Constructal thermodynamics. International Journal of Heat and Technology 34(1): S1S8. https://doi.org/10.18280/ijht.34S101

[14] Zhang K, Du J, Liu X, Zhang H. (2018). Molten salt flow and heat transfer in paddle heat exchangers. International Journal of Heat and Technology 34(1): S43-S50. https://doi.org/10.18280/ijht.34S101

\section{NOMENCLATURE}

\section{$c, C$}

$e x, \overline{e x}$

$E X$

$\dot{E X}$

$g, \bar{g}$

$h$,

H

$\dot{m}$

$n$

$p$

$\frac{\dot{\mathrm{Q}}}{R}$

$\frac{\mathrm{Q}}{R}$

\section{Greek symbols}

$\begin{array}{ll}\eta & \text { efficiency, }- \\ \tau & \text { time interval, } \mathrm{s}\end{array}$

\section{Subscripts}

$\begin{array}{ll}\text { C } & \text { Chemical } \\ \text { DES } & \text { Destruction } \\ \text { DW } & \text { Dwell } \\ \text { IN } & \text { Inlet, input } \\ \text { IRR } & \text { Irreversible } \\ \text { M } & \text { Mechanical } \\ \text { OUT } & \text { Outlet } \\ \text { OV } & \text { Overall }\end{array}$

\section{Superscripts}

$\begin{array}{ll}\text { PLS } & \text { Pulse } \\ \text { R } & \text { Reference state } \\ \text { REV } & \text { Reversible } \\ \text { RR } & \text { Restricted Ref. } \\ \text { SH } & \text { Shell side } \\ \text { TB } & \text { Tube side } \\ \text { T } & \text { Thermal } \\ p, v & \text { Isobaric, isocoric }\end{array}$

\section{Acronyms}

$\begin{array}{ll}\text { BOP } & \text { Balance Of Plant } \\ \text { BZ } & \text { Breeding Zone } \\ \text { CAS } & \text { CASsette } \\ \text { DEMO } & \text { DEMOnstration fusion power reactor } \\ \text { DIV } & \text { DIVertor } \\ \text { EES } & \text { Energy Storage System } \\ \text { FW } & \text { First Wall } \\ \text { HCPB } & \text { Helium Cooled Pebble Bed } \\ \text { HCSG } & \text { Helical Coil Steam Generator } \\ \text { IHTS } & \text { Intermediate Heat Transfer System } \\ \text { IHX } & \text { Intermediate Heat eXchanger } \\ \text { LHV } & \text { Lower Heating Value } \\ \text { OTSG } & \text { Once Through Steam Generator } \\ \text { PCS } & \text { Power Conversion System } \\ \text { PFC } & \text { Plasma Facing Components } \\ \text { PHTS } & \text { Primary Heat Transfer System } \\ \text { VV } & \text { Vacuum Vessel } \\ \text { WCLL } & \text { Water Cooled Lithium Lead }\end{array}$

